


\section{About IJMA [last updated October, $\left.1^{\text {st }}, 2021\right]$}

$\checkmark$ International Journal of Medical Arts is the Official Journal of the Damietta Faculty of Medicine, AlAzhar University, Egypt

$\checkmark$ It is an International, Open Access, Double-blind, Peer-reviewed Journal

$\checkmark$ Published four times a year

$\checkmark$ The First Issue was published in July 2019

$\checkmark$ Published under the following license: Creative Commons Attribution-ShareAlike 4.0 International Public License (CC BY-SA 4.0). It had updated from the Creative Commons license [CC BY] in volume 2, Issue 4, October 2020 About IJMA

$\checkmark$ The Egyptian Knowledge Bank hosts the web site of IJMA

$\checkmark$ The Egyptian Knowledge Bank supports IJMA

$\checkmark$ IJMA follows the regulations of the International Committee of Medical Journal Editors

$\checkmark$ IJMA is indexed in the "Directory of Open Access Journals" [15 January 2021].

$\checkmark$ IJMA is indexed in J-Gate [29-6-2021]

$\checkmark$ IJMA is a member of the International Society of Managing and Technical Editors

$\checkmark$ Listed in "Index Copernicus", "Publons", "Academic resource index [ResearchBib]" "Electronics journal library", "Eurasian Scientific Journal Index", "WorldCat" Superstar Journal Database, and "Citefactor"

$\checkmark$ IJMA introduced to the search engine [BASE] through DOAJ

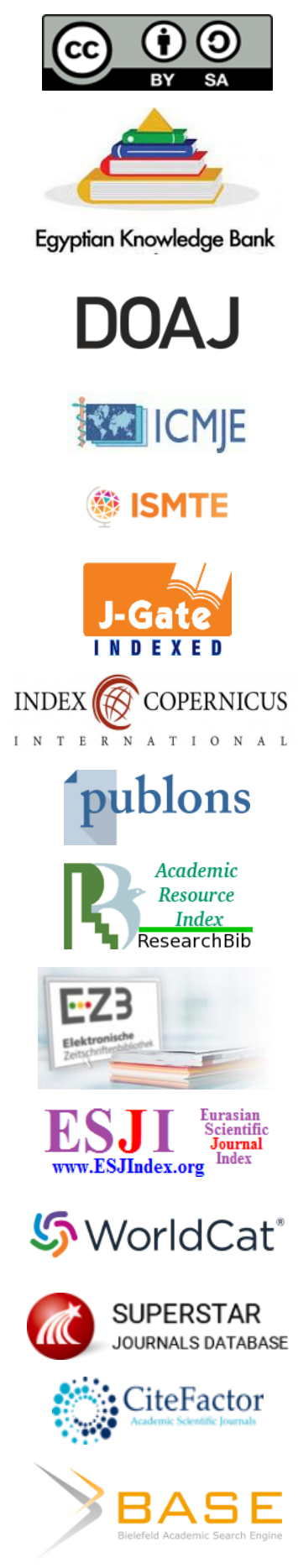




Available online at Journal Website
https://ijma.journals.ekb.eg/
Main subject [Respiratory Medicine] ${ }^{*}$

Original Article

\title{
Assessing the Safety and Efficacy of Thoracoscopic Lung Biopsy in Patients with Interstitial Lung Disease
}

\author{
Mohamed Mustafa Mahmoud Elsheikh [1], Hussein Ahmad Abo-Elyazed [2], Kamel Abdelghaffar [1], Atef Wahdan \\ Alrifai [1], Salah Eldeen Semary [3]. \\ 1 Department of Chest Diseases, Damietta Faculty of Medicine, Al-Azhar University, Egypt. \\ 2 Department of Chest Diseases, Faculty of Medicine, Al-Azhar University, Egyptl. \\ ${ }^{3}$ Department of Pathology, Damietta Faculty of Medicine, Al-Azhar University, Egypt.
}

Corresponding author: Mohamed Mustafa Mahmoud Elsheikh

Email: alshykhmhmd457@gmail.com

Submission date: February 15, 2021; Acceptance date: August 17, 2021

DOI: $10.21608 / I J M A .2021 .63433 .1265$

DOAJ

\section{ABSTRACT}

Background: Interstitial lung disease [ILD] is a difficult-to-treat disease. The patient continues treatment for his/her whole life. However, certain causes - when diagnosed - could change their treatment plan. Radiological investigations cannot elicit the underlying pathology $100 \%$. Thus, transthoracic lung biopsy is of utmost importance, especially in undiagnosed patients. But, it is not free of risk, and thus, its use is still controversial.

Aim of the work: This work aims to evaluate the role of medical thoracoscopic lung biopsy [TLB] in diagnosing diffuse parenchymal lung diseases.

Patients and Methods: Fifty patients with diffuse lung infiltrate on high-resolution computed tomography [HCRT] of unconfirmed diagnosis were included. All patients have been submitted to detailed clinical examination and specific laboratory investigations. Furthermore, all had high resolution computed tomography, pulmonary function tests], echocardiography, arterial blood gas analysis, and bronchoalveolar lavage assessment. The thoracoscopic lung biopsy was performed under local anesthesia. The specimens were preserved in formalin containing cups till examination. Patients were followed up, and any complications were documented.

Results: The lung HCRT revealed ground-glass opacity [44\%], reticulonodular interstitial pattern [38\%], honeycombing [14\%], crazy paving [10.0\%], and consolidation [20.0\%]. The histopathology revealed alveolar proteinosis [2.0\%], alveolar hemosidrosis [2.0\%], hypersensitivity pneumonitis [24.0\%], sarcoidosis [8.0\%], nonspecific interstitial pneumonia [20\%], Idiopathic pulmonary fibrosis [12.0\%], respiratory bronchiolitis ILD [18\%], and desquamative ILD [14.0\%]. All patients positive on HCRT had pathological change. Complications were [12\%] bulla in partnehymea, [4\%] plural disear, [2\%] pneumothorax, and $2 \%$ died during follow up duration.

Conclusion: TLB is an effective and relatively safe, minimally invasive intervention for interstitial lung disease diagnosis. Accordingly, it must be considered a standard diagnostic tool for undiagnosed suspected cases.

Keywords: Interstitial Lung Disease; Transthoracic; Lung Biopsy; Efficacy; Safety.

This is an open-access article registered under the Creative Commons, ShareAlike 4.0 International license [CC BY-SA 4.0] [https://creativecommons.org/licenses/by-sa/4.0/legalcode.

Citation: Elsheikh MMM, Abo-Elyazed HA, Abdelghaffar K, Alrifai AW, Semary SE. Assessing the Safety and efficacy of Thoracoscopic Lung Biopsy in Patients with Interstitial Lung Disease. IJMA 2021; 3 [4] October-December: 1777-1783. [DOI: 10.21608/IJMA.2021.63433.1265].

${ }^{*}$ Main subject and any subcategories have been classified according to the research topic 


\section{INTRODUCTION}

Interstitial lung disease [ILD], also recognized as diffuse parenchymal lung disease, refers to a heterogeneous group of over 150 unconnected disorders. Each ILD form has its own distinct clinical, radiological, and pathological manifestations. Several key differences are due to variations in the anatomic distribution of the disease. ILD represented about $15 \%$ of the respiratory disease in general populations ${ }^{[1]}$.

In 2020, ILD has been reported in 595,000 people all over the globe. With very high mortality rate $[471,000$ deaths]. The evolution in these disorders' classification has been driven by epidemiologic, clinical, radiologic, biochemical, genetic, and pathological investigation [2].

ILD in the non-immunocompromised subject is often a problematic challenge from clinical point of view, especially when specific diagnosis clues are found after thorough assessment, investigations and chest imaging. Traditionally, high resolution computed tomography [HRCT] bronchoalveolar lavage and Transbronchial biopsy [TBLB] the next steps ${ }^{[3]}$.

Thoracoscopy has been performed by professional pulmonologists, with satisfactory safety and efficacy, for many decades ${ }^{[4]}$.

The recent advances in video equipments and more sophisticated, fine instruments has expanded its indications. There are encouraging reports for lung biopsy by medical thoracoscopy in ILD in immune-compromised subjects. However, this procedure gained a little acceptance among pulmonologists ${ }^{[5]}$.

Medical thoracoscopic lung biopsy in the diagnosis of interstitial lung disease [ILD] can be considered a second choice after the failure of bronchoalveolar lavage [BAL] and [TBLB] to provide the diagnosis, and this procedure has some advantages over surgical lung biopsy [SLB]. The possibility to obtain numerous biopsies under respectable visual guidance and lower complication rate are the most important advantages ${ }^{[6]}$.

Others argued that treatment did not differ widely and mortality did not decrease with confirmation of diagnosis by biopsy ${ }^{[7]}$.

This view would be acceptable if empirical management always leads to an improvement, but when the reverse is the case, the next step in treatment is difficult and becomes worse if drug-induced unwanted side effects have settled [especially side effects related to high dose of steroids]. A definite diagnosis by the biopsy permits clinicians and their patients to build up a clear plan of management, based on weighing benefit-risk ratio [7].

\section{AIM OF THE WORK}

This work aims to assess the role of the medical thoracoscopic lung biopsy in diagnosis of diffuse parenchymal lung diseases.

\section{PATIENTS AND METHODS}

This study included 50 patients with diffuse lung infiltrates on high-resolution CT [HRCT] chest of unconfirmed diagnosis. The study was conducted between April 2019 and December 2020 at the chest department, AlAzhar University hospital [Damietta].

\section{Ethical consideration:}

The study protocol was approved by our institution's research and ethics committee [IRB number: 00012367-1904-002]. All patients signed informed consents, and all study procedures were completed according to local ethical codes that coincide with Helsinki declaration codes.

Patients with diffuse lung infiltrate on high-resolution CT chest with the unconfirmed diagnosis were included in the study. Otherwise, patients with one or more of the procedure contraindications were excluded from the study.

Contraindications include coagulation abnormalities [prothrombin level less than $50 \%$ or platelet count $<70,000$ cells/cc], severe respiratory failure $\left[\mathrm{PaCO}_{2}>60 \mathrm{mmHg}\right.$, mechanical ventilation, radiographic findings suggestive of significant pleural adhesions or major bullous degeneration of the lung, severe pulmonary hypertension, cardiac disorders, heart failure, renal failure or liver cell failure.

All patients gave the full medical history. Besides, they have been submitted to systematic clinical examination and specific laboratory investigations directed to markers of connective tissue diseases.

Furthermore, all patients have undergone high resolution computed tomography, pulmonary function tests [PFTs], echocardiography, arterial blood gas analysis, and bronchoalveolar lavage [BAL] assessment.

The thoracoscopic lung biopsy was performed under local anesthesia as described previously [8]. 


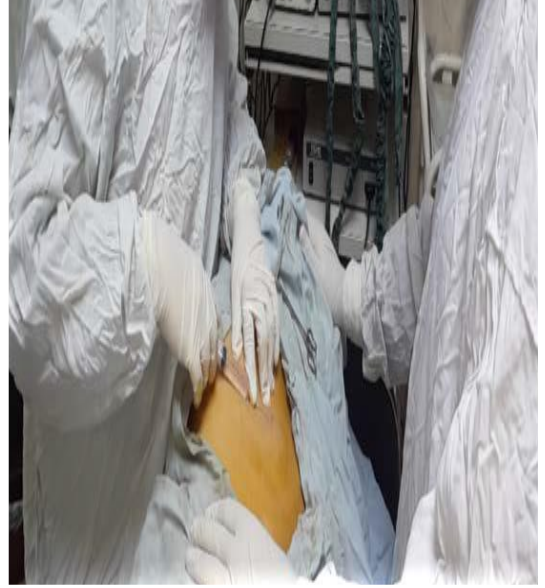

Figure [1]: Administration of local anesthesia

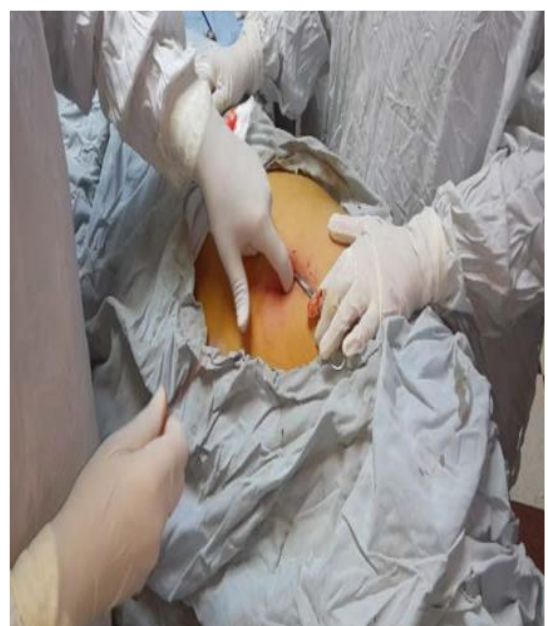

Figure [4]: Palpation by the index finger

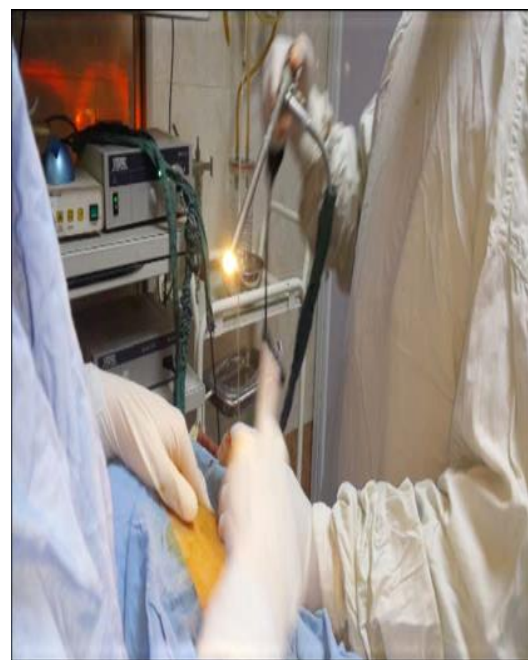

Figure [7]: Thoracoscope introduction

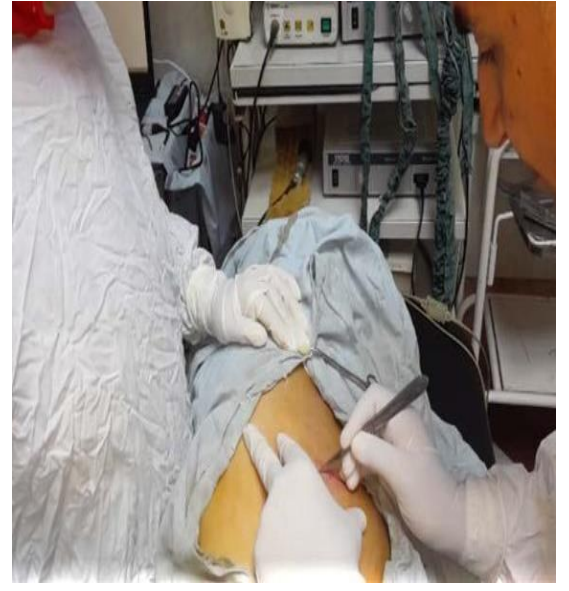

Figure [2]: Incision

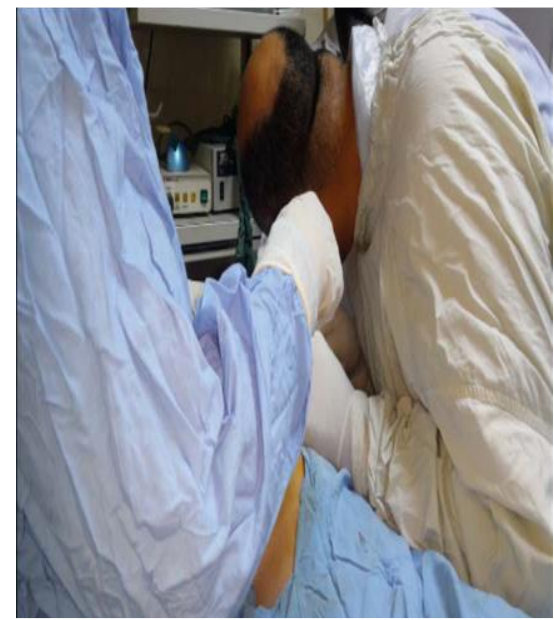

Figure [5]: Hearing air entry

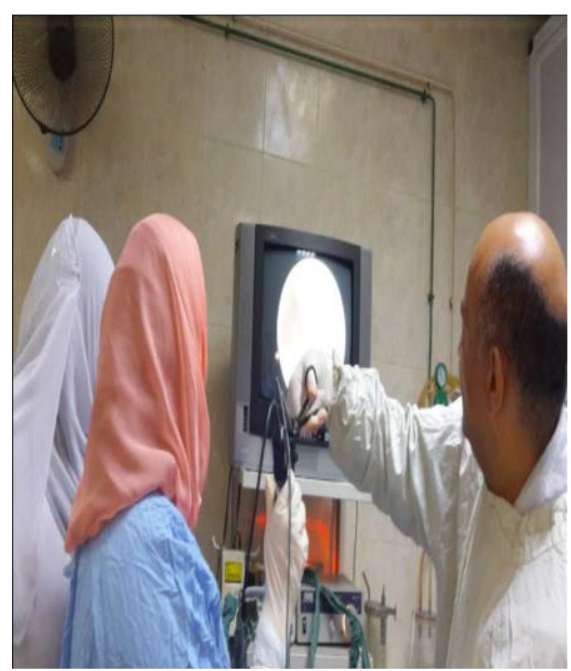

Figure [8]: Taking the biopsy

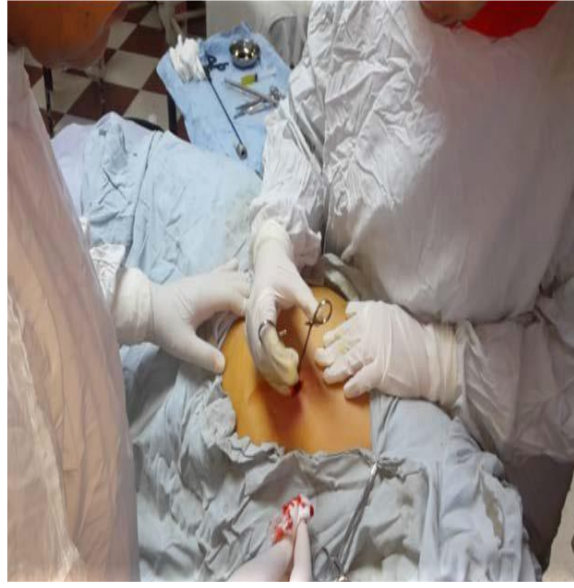

Figure [3]: Dissection

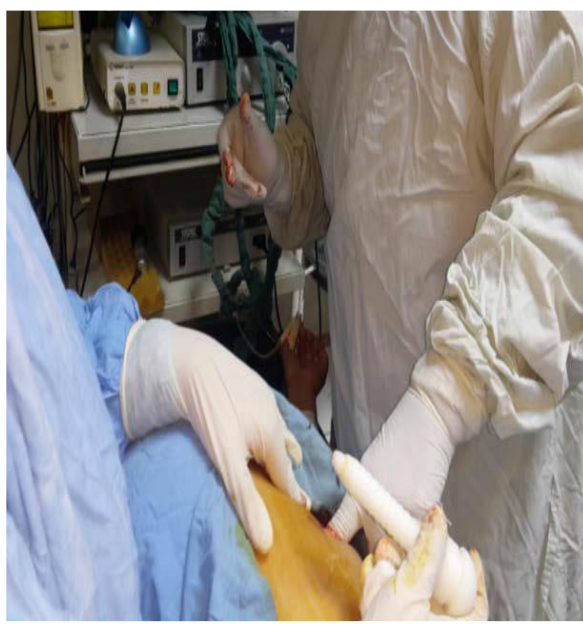

Figure [6]: Trocar insertion

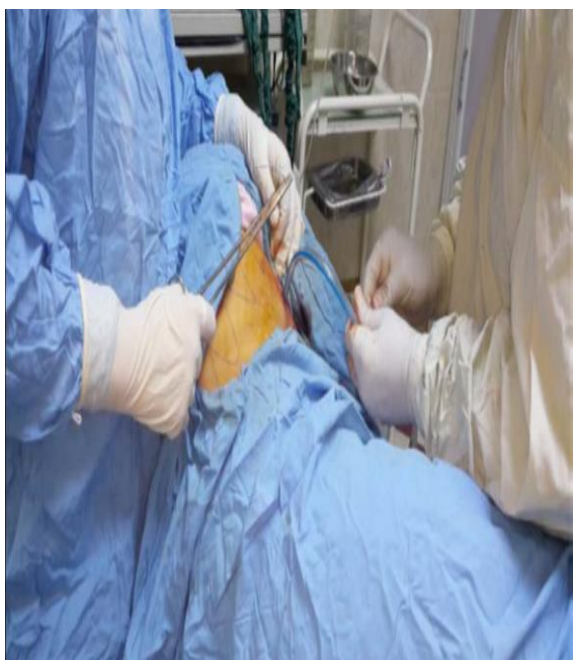

Figure [9]: Tube insertion and wound closure 
Table [1]: Electrolytes, arterial blood gases, pulmonary function tests, electrocardiogram, and X-ray among studied populations

\begin{tabular}{|c|c|c|}
\hline & & Patients [n=50] \\
\hline \multirow[t]{4}{*}{ Electrolytes } & $\mathrm{Na}[\mathrm{mEq} / \mathrm{L}]$ & $133.02 \pm 0.86$ \\
\hline & $\mathrm{K}[\mathrm{mEq} / \mathrm{L}]$ & $4.14 \pm 0.15$ \\
\hline & lonized $\mathrm{Ca}$ [mg/dL] & $3.65 \pm 0.12$ \\
\hline & $\mathrm{Mg}[\mathrm{mg} / \mathrm{dL}]$ & $2.66 \pm 0.78$ \\
\hline \multirow[t]{4}{*}{ ABGs } & $\mathrm{pH}$ & $7.41 \pm 0.0557$ \\
\hline & $\mathrm{PaO}_{2}$ & $66.16 \pm 6.62$ \\
\hline & $\mathrm{SaO}_{2}$ & $93.7 \pm 2.91$ \\
\hline & $\mathrm{HCO}_{3}$ & $23.56 \pm 5.076$ \\
\hline \multirow[t]{3}{*}{ Pulmonary function tests } & FVC $\%$ & $56.43 \pm 14.76$ \\
\hline & $\mathrm{FEV}_{1} \%$ & $67.9 \pm 7.17$ \\
\hline & FEV1/FVC ratio & $96.4 \pm 10.53$ \\
\hline \multirow[t]{3}{*}{ ECG } & Normal & $36[72.0 \%]$ \\
\hline & Sinus tachycardia & $9[18.0 \%]$ \\
\hline & P pulmonale & $5[10.0 \%]$ \\
\hline \multirow[t]{5}{*}{ X-ray } & Normal & $26[52.0 \%]$ \\
\hline & Nodular & $8[16.0 \%]$ \\
\hline & Reticular & $2[4.0 \%]$ \\
\hline & Hilar LN & $4[8.0 \%]$ \\
\hline & Small lung volume & $10[20.0 \%]$ \\
\hline
\end{tabular}

Table [2]: Different data according to Warrick score among the studied patients

\begin{tabular}{|c|c|c|c|c|c|}
\hline \multicolumn{2}{|c|}{ Parameters } & Mild[n=23] & Moderate[n=22] & Severe[n=5] & $p$ \\
\hline \multicolumn{2}{|c|}{ Warrick score } & $11.12 \pm 3.41$ & $20.18 \pm 3.26$ & $29.2 \pm 0.936$ & $<0.001^{*}$ \\
\hline \multicolumn{2}{|c|}{ 6-min walk test } & $454.5 \pm 107.1$ & $431.8 \pm 82.37$ & $218.1 \pm 34.21$ & $<0.001^{*}$ \\
\hline \multicolumn{2}{|c|}{ B-lines distance } & $4.82 \pm 1.33$ & $5.29 \pm 1.34$ & $5.46 \pm 1.31$ & $0.003^{*}$ \\
\hline \multicolumn{2}{|l|}{$\mathrm{PaO}_{2}$} & $69.21 \pm 6.55$ & $67.09 \pm 6.83$ & $64.43 \pm 7.39$ & $0.003^{*}$ \\
\hline \multicolumn{2}{|l|}{ FVC } & $62.13 \pm 7.04$ & $59.36 \pm 5.73$ & $56.45 \pm 8.61$ & $0.001^{*}$ \\
\hline \multirow[t]{4}{*}{ Symptoms } & Dyspnea & 8 [34.8\%] & 7 [31.8\%] & $1[20 \%]$ & \multirow[t]{4}{*}{0.752} \\
\hline & Dry cough & 8 [34.8\%] & $8[36.4 \%]$ & $1[20 \%]$ & \\
\hline & Easy fatigability & $6[26.1 \%]$ & $5[22.7 \%]$ & $3[60 \%]$ & \\
\hline & Fever & $1[4.3 \%]$ & $2[9.1 \%]$ & $0[0.0 \%]$ & \\
\hline
\end{tabular}

Table [3]: Complications and hospital stay among studied populations

\begin{tabular}{|c|c|c|c|}
\hline & & \multicolumn{2}{|c|}{ Patients [n=50] } \\
\hline & & $\mathrm{N}$ & $\%$ \\
\hline \multirow[t]{4}{*}{ Complications } & Bulla in partnehymea & 6 & $12.0 \%$ \\
\hline & Plural Disear & 2 & $4.0 \%$ \\
\hline & Pneumothorax & 1 & $2.0 \%$ \\
\hline & Mortality & 1 & $2.0 \%$ \\
\hline \multirow[t]{2}{*}{ Hospital stay duration } & Mean \pm SD & \multicolumn{2}{|c|}{$4.94 \pm 0.77$} \\
\hline & Median [Range] & \multicolumn{2}{|c|}{$5[4-6]$} \\
\hline \multirow[t]{2}{*}{ Follow up duration } & Mean \pm SD & \multicolumn{2}{|c|}{$5.28 \pm 0.83$} \\
\hline & Median [Range] & \multicolumn{2}{|c|}{$6[4-6]$} \\
\hline
\end{tabular}


Table [4]: Relation between computed tomography and histopathology reports

\begin{tabular}{lccccc}
\hline & \multicolumn{3}{c}{ CT findings } \\
\cline { 2 - 6 } & GGO & CP & Cons. & RIP & HC. \\
& {$[\mathrm{n}=22]$} & {$[\mathrm{n}=5]$} & {$[\mathrm{n}=10]$} & {$[\mathrm{n}=19]$} & {$[\mathrm{n}=7]$} \\
\hline Alveolar proteinosis & $1[4.5]$ & $0[0.0]$ & $0[0.0]$ & $0[0.0]$ & $0[0.0]$ \\
\hline Alveolar hemosidrosis & $0[0.0]$ & $1[20.0]$ & $0[0.0]$ & $0[0.0]$ & $0[0.0]$ \\
\hline Hypersensitivity pneumonitis & $10[45.5]$ & $1[20.0]$ & $0[0.0]$ & $3[15.8]$ & $0[0.0]$ \\
\hline Sarcoidosis & $0[0.0]$ & $0[0.0]$ & $0[0.0]$ & $4[21.1]$ & $0[0.0]$ \\
\hline Nonspecific interstitial pneumonia & $2[9.1]$ & $1[20.0]$ & $4[40.0]$ & $3[15.8]$ & $2[28.6]$ \\
\hline Idiopathic pulmonary fibrosis & $3[13.6]$ & $0[0.0]$ & $0[0.0]$ & $3[15.8]$ & $3[42.9]$ \\
\hline Respiratory bronchiolitis ILD & $6[27.3]$ & $1[20.0]$ & $0[0.0]$ & $6[31.6]$ & $2[28.6]$ \\
\hline Desquamative ILD & $0[0.0]$ & $1[20.0]$ & $6[60.0]$ & $0[0.0]$ & $0[0.0]$ \\
\hline
\end{tabular}

GGO: Ground glass opacity; CP: Crazy paving; Cons.: consolidation; RIP: Reticular interstitial pattern; HC: honeycombing

Here, we presented a male patient, 50 years old, who had diabetes, hypertension, and ischemic heart disease [IHD]. He presented with dyspnea and easy fatigability. Clinically, he had cyanosis, clubbing, bilateral basal consonating [Velcro] crepitation. Chest X-ray [figure 10] revealed bilateral central infiltration [increased bronchovascular markings]. The ultrasound revealed multiple B lines and thick pleural line; while CT Chest revealed reticulonodular opacification and ground-glass appearance.

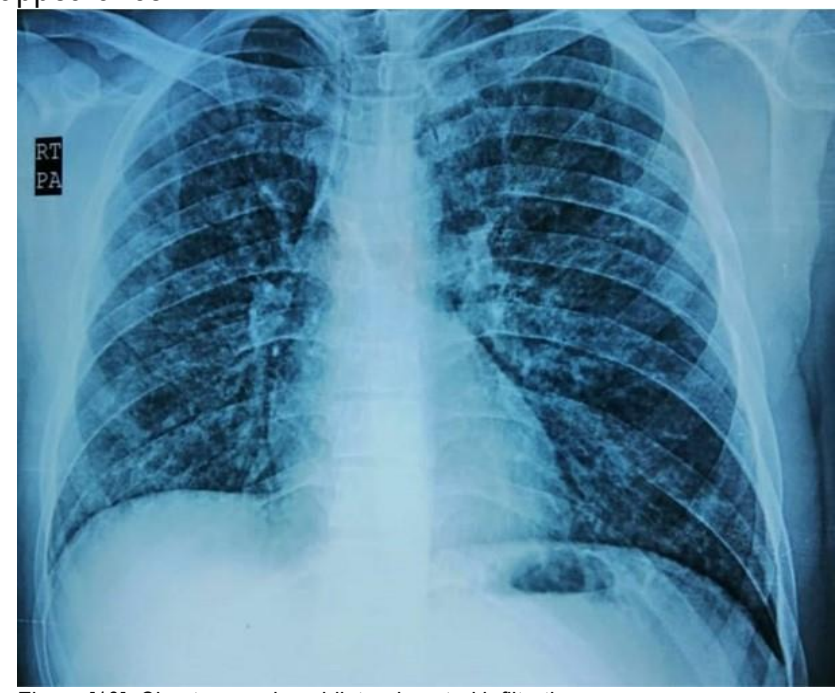

Figure [10]: Chest x-ray show bilateral central infiltration

\section{DISCUSSION}

A specific diagnosis remains unavailable to one-third of all patients with ILD even after using computerized tomography, bronchoscopy, bronchoalveolar lavage examination, and transbronchial Lung Biopsies [TBLBs]. So, for this sizeable group of patients, the only option remaining is the SLB. However, surgery had its risks. In recent years Video-assisted Thoracoscopic Surgery [VATS] has replaced the older, more invasive method of performing a minithoracotomy in these patients [10]. The current work aimed to evaluate thoracoscopic lung biopsy's safety and efficacy in patients with interstitial lung diseases. A prospective study was conducted in the endoscopy unit in the chest department, Al-Azhar University hospital [Damietta]. It included 50 patients with suspected ILD. Results are in line

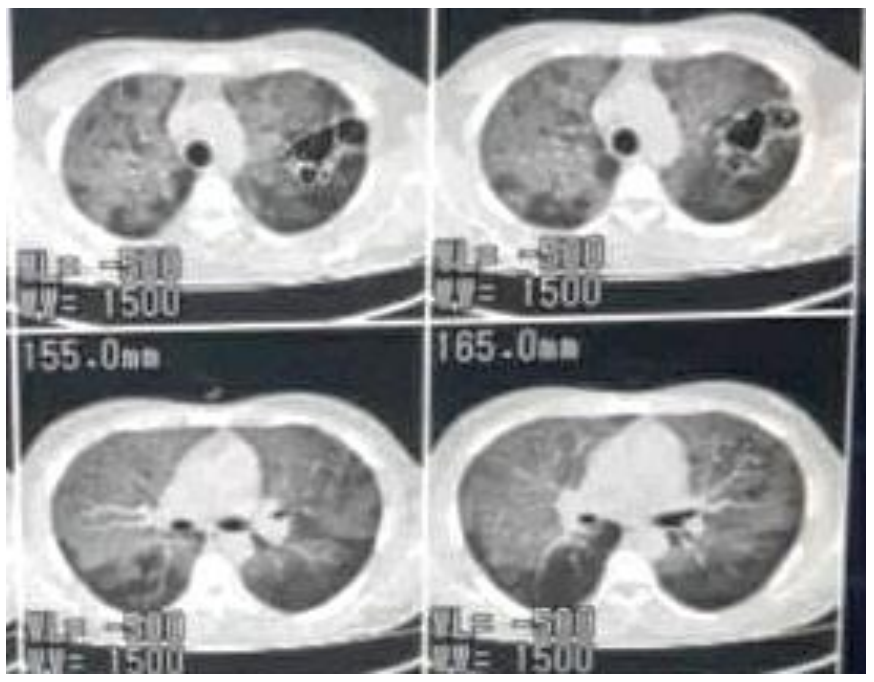

Figure [11]: HRCT showed multiple areas of central alveolar consolidation with air trapping and cystic change

with Lieberman et al. [11], who included Forty-seven patients with suspicious ILD for SLB. The mean age was $57.4 \pm 12.8$, and $55.3 \%$ were females, $44 \%$ were smokers, and there were 33 diabetic patients and 17 COPDs. Furthermore, Kreider et al. [12] revealed an average age of 58 years [range, 38 to 84 years], and 56\% were women. Fifty percent were current or former smokers. Also, the current work results are in line with Fibla et al. [13]. They reported that mean FVC was $75 \%[56.43 \pm 14.76 \%$ in the current work]; FEV1: $76.1 \%[67.9 \pm 7.17 \%$ in the current study] FEV1/FVC was $86 \%$, TLC was $74 \%$.

Regarding CT findings, the current study showed that the most prevalent finding was ground-glass opacity [GGO; $44 \%$ ], and the least prevalent finding was crazy paving [10\%]. These findings are supported by Goldin et al. [14]. They reported that HRCT revealed $92.9 \%$ pulmonary fibrosis [PF], 49.4\% pure ground-glass opacity [pGGO], and 
$37.2 \%$ honeycomb cysts [HCs]. Furthermore, Luo et al. [15] revealed that distinguishing HRCT features were groundglass opacities, reticular lines, patchy consolidation, bullae, pleural thickening, honeycombing, subpleural lines, emphysematous changes, pleural effusion and enlargement of mediastinal lymph nodes patchy nodules among $87.5 \%$, $65.6 \%, 43.8 \%, 25 \%, 21.9 \%, 21.9 \%, 18.8 \%, 12.5 \%, 6 \%, 6 \%$ and $6 \%$ in a successive order.

Because the use of X-ray for ILD detection is not sensible [as it is normal in the majority of patients, especially in early disease stages [ $52 \%$ were normal in the current study]], HRCT is the "gold" standard imaging modality for the diagnosis and monitoring of ILD. HRCT images and characteristic histopathological data can be highly suggestive for characteristic diagnoses in such patients. Current data supports the use of LUS, to detect ILD by the detection of and evaluation of B-lines, a sonographic marker of the diffuse pulmonary interstitial syndrome [16].

Currently, the role of SLB is still debated. However, its main advantage over different radiological investigations [Xray, ultrasound, or CT chest] is the pathology's definite diagnosis, which leads to a change in the treatment regimen. For example, the diagnosis of sarcoidosis shortens therapy [from a whole life treatment to a few months]. Besides, it differentiates the prognosis of different conditions [e.g., desquamative ILD had a good prognosis, which advocates continuous treatment].

Despite the advent of video-assisted thoracoscopic surgery [VATS] for lung biopsy and the progress of postsurgery intensive care, many physicians are overcautious on the balance between the efficacy of VATS on diagnosis and the risks of SLB [17]. Luo et al. [15] included a total of 811 patients diagnosed as ILD during 5 years, and only 32 [3.9\%] patients accepted VATS. In these selected ILD patients, the diagnosis was changed from the previous diagnosis in $84.4 \%$ after SLB. The site and number of biopsies may affect the diagnostic efficacy of VATS. Morell et al. ${ }^{[18]}$ found that diagnoses from the lingula and middle lobes coincided with those from other lobes. In their study with 41 biopsies, the biopsy site was determined by the abnormalities on CT scan with one biopsy site in most cases and no biopsy obtained from the lingula or middle lobe. These data were compared to the study published by Fibla et al. [13]. They reported that a single biopsy site might be sufficient to obtain a definite diagnosis for most patients [71.9\%]. Morris and Zamvar [19] revealed that a definite pathological diagnosis was made in $74.2 \%$ of cases following VATS biopsy. A change in treatment was initiated in $47.2 \%$ of patients, including in $80 \%$ of patients diagnosed with hypersensitivity pneumonitis and $60 \%$ of patients diagnosed with sarcoidosis. A positive response to treatment was experienced in $58 \%$ of patients who changed treatment. Only $54 \%$ of patients who received a consensus diagnosis of UIP after VATS lung biopsy had been given a differential diagnosis of "probable UIP" at CT scan. $15 \%$ of patients who received a differential diagnosis of "probable UIP" at CT scan had their diagnosis changed to Hypersensitivity Pneumonitis after lung biopsy.

As regard complications of the patients show that $6[12 \%]$ had Bulla in partnehymea, two [4\%] had plural disear, one [2\%] had Pneumothorax, and one [2\%] died. Hospital stay duration was ranged between $4-6$ days with a mean value of $4.94 \pm 0.77$ days. Follow-up duration was ranged between 4-6 months with a mean value of $5.28 \pm 0.83$ months. Lieberman et al. [11] included 47 patients. Lung tissue was obtained via a thoracoscopic approach in all, but two had mini-thoracotomy. The mean operative time was 51.1 minutes [18-123], median hospital stay was two days [1-18]. Most [87.2\%] of the patients were discharged within 72 hours. Thirty-day mortality for elective surgery was $4.5 \%$ [2/44]. Post-operative complications occurred in about onethird of the patients. Complications in elective procedures included pneumothorax [10.4\%], re-intubation [5.4\%] and prolonged intubation [2.7\%]. Full concordance of radiographic diagnosis with the final diagnosis was significantly higher when reviewed by a cardiothoracic radiologist [60.5\% vs. $21.3 \%$ ]. The preoperative clinical diagnosis was fully concordant with the final diagnosis in only $28.2 \%$ of cases. Furthermore, Jeon et al.[20] revealed that no major surgical complications or deaths were reported in either group, and non-intubated VATS biopsies were safely performed in subjects with relatively low carbon monoxide diffusing capacity $[\mathrm{P}=0.08]$ or poor American Society of Anesthesiologists physical status scores [ASA] $[P=0.02]$.

In conclusion, thoracoscopic lung biopsy is an effective and relatively safe procedure to reach the final diagnosis in undiagnosed patients with suspected interstitial lung disease. However, as an invasive procedure, it must be resorted to undiagnosed patients irrespective of the use of computed tomography or promising lung ultrasound. Besides, thoracoscopic lung biopsy provides significant therapeutic benefit and could be considered the gold standard in diagnosing ILD. However, as the small number of included patients represented a limiting step of the current work, we could not generalize our results, and future studies are still required.

Financial and Non-financial Relationships and Activities of Interest

None 


\section{REFERENCES}

1. Annapurna S, Badarke P, Chandra E. Study of Interstitial Lung Disease with reference to radiological profile. Asian $\mathrm{J}$ Med Radiol Res. 2018; 6 [1]: 15-21. DOI: /10.21276/ ajmrr.2018.6. 1.5

2. Zhang $H$, Chen L, Wu L, Huang J, Li H, Wang X, Weng $H$. Diagnostic and prognostic predictive values of circulating $\mathrm{KL}$ 6 for interstitial lung disease: A PRISMA-compliant systematic review and meta-analysis. Medicine [Baltimore]. 2020; 99[16]: e19493. DOI: 10.1097/MD.0000000000019493.

3. Sambataro D, Sambataro G, Pignataro F, Zanframundo G, Codullo V, Fagone $\mathrm{E}$, et al. Patients with Interstitial Lung Disease Secondary to Autoimmune Diseases: How to Recognize Them? Diagnostics [Basel]. 2020 Apr 9; 10[4]:208. DOI: $10.3390 /$ diagnostics 10040208 .

4. El-Hadidy TA, Rezk NASA. Diagnostic accuracy and safety of rigid medical thoracoscopy in undiagnosed pleural effusion and ILD: Retrospective study of 100 patients. Egypt J Chest Dis Tub 2016; 65 [1]: 199-203. DOI: 10.1016/j.ejcdt.2015.10. 003

5. Qureshi RA, Soorae AA. Efficacy of thoracoscopic lung biopsy in interstitial lung diseases: comparison with open lung biopsy. J Coll Physicians Surg Pak. 2003; 13[10]:600-3. DOI: 10. 2003/JCPSP.600603.

6. Romagnoli M, Colby TV, Berthet JP, Gamez AS, Mallet JP, Serre I, et al. Poor Concordance between Sequential Transbronchial Lung Cryobiopsy and Surgical Lung Biopsy in the Diagnosis of Diffuse Interstitial Lung Diseases. Am J Respir Crit Care Med. 2019; 199[10]:1249-1256. DOI: 10.1164/rccm. 201810-19470C.

7. Sindhwani G, Shirazi N, Sodhi R, Raghuvanshi S, Rawat J. Transbronchial lung biopsy in patients with diffuse parenchymal lung disease without 'idiopathic pulmonary fibrosis pattern' on HRCT scan-Experience from a tertiary care center of North India. Lung India. 2015 Sep-Oct; 32[5]:453-6. DOI: 10.4103/0970-2113.164148.

8. Samejima J, Tajiri M, Ogura T, Baba T, Omori T, Tsuboi M, Masuda M. Thoracoscopic lung biopsy in 285 patients with diffuse pulmonary disease. Asian Cardiovasc Thorac Ann. 2015 Feb; 23[2]:191-7. DOI: 10.1177/0218492314550724.

9. Rahman NM, Ali NJ, Brown G, Chapman SJ, Davies RJ, Downer NJ, Gleeson FV, Howes TQ, Treasure T, Singh S, Phillips GD; British Thoracic Society Pleural Disease Guideline Group. Local anaesthetic thoracoscopy: British Thoracic Society Pleural Disease Guideline 2010. Thorax. 2010 Aug; 65 Suppl 2:ii54-60. DOI: 10.1136/thx.2010. 137018

10. Hernandez-Arenas LA, Lin L, Yang Y, Liu M, Guido W, Gonzalez-Rivas D, Jiang G, Jiang L. Initial experience in uniportal subxiphoid video-assisted thoracoscopic surgery for major lung resections. Eur J Cardiothorac Surg. 2016 Dec; 50 [6]:1060-1066. DOI: 10.1093/ejcts/ezw189.
11. Lieberman S, Gleason JB, llyas MIM, Martinez F, Mehta JP, Savage EB. Assessing the Safety and Clinical Impact of Thoracoscopic Lung Biopsy in Patients with Interstitial Lung Disease. J Clin Diagn Res. 2017 Mar; 11[3]:OC57-OC59. DOI: 10.7860/ JCDR/2017/20281.9626.

12. Kreider ME, Hansen-Flaschen J, Ahmad NN, Rossman MD, Kaiser LR, Kucharczuk JC, Shrager JB. Complications of video-assisted thoracoscopic lung biopsy in patients with interstitial lung disease. Ann Thorac Surg. 2007 Mar; 83 [3]:1140-4. DOI: 10.1016/j.athoracsur.2006.10.002.

13. Fibla JJ, Molins L, Blanco A, Royo I, Martínez Vallina P, et al. Video-assisted thoracoscopic lung biopsy in the diagnosis of interstitial lung disease: a prospective, multi-center study in 224 patients. Arch Bronconeumol. 2012 Mar;48[3]:81-5. DOI: 10.1016/j.arbres. 2011.11.002.

14. Goldin JG, Lynch DA, Strollo DC, Suh RD, Schraufnagel DE, Clements PJ, et al. Scleroderma Lung Study Research Group. High-resolution CT scan findings in patients with symptomatic scleroderma-related interstitial lung disease. Chest. 2008 Aug; 134[2]:358-367. DOI: 10.1378/chest.07-2444.

15. Luo Q, Han Q, Chen X, Xie J, Wu L, Chen R. The diagnosis efficacy and safety of video-assisted thoracoscopy surgery [VATS] in undefined interstitial lung diseases: a retrospective study. J Thorac Dis. 2013 Jun;5[3]:283-8. DOI: 10.3978/j.issn. 2072-1439.2013.04.12.

16. Manolescu D, Davidescu L, Traila D, Oancea C, Tudorache V. The reliability of lung ultrasound in assessment of idiopathic pulmonary fibrosis. Clin Interv Aging. 2018 Mar 22; 13:437449. DOI: $10.2147 / \mathrm{CIA} . S 156615$.

17. Sugino $K$, Otsuka $H$, Matsumoto $Y$, Nakamura $Y$, Matsumoto $\mathrm{K}$, Azuma $\mathrm{Y}$, et al. The role of video-assisted thoracoscopic surgery in the diagnosis of interstitial lung disease. Sarcoidosis Vasc Diffuse Lung Dis. 2019; 36 [2]: 148-156. DOI: $10.36141 /$ svdld.v36i2.7797.

18. Morell F, Reyes L, Doménech G, De Gracia J, Majó J, Ferrer J. [Diagnoses and diagnostic procedures in 500 consecutive patients with clinical suspicion of interstitial lung disease]. Arch Bronconeumol. 2008; 44[4]:185-91. PMID: 18423179.

19. Morris D, Zamvar V. The efficacy of video-assisted thoracoscopic surgery lung biopsies in patients with Interstitial Lung Disease: a retrospective study of 66 patients. J Cardiothorac Surg. 2014 Mar 10; 9:45. DOI: 10.1186/17498090-9-45.

20. Jeon CS, Yoon DW, Moon SM, Shin S, Cho JH, Lee SM, Ahn HJ, Kim JA, Yang M. Non-intubated video-assisted thoracoscopic lung biopsy for interstitial lung disease: a single-center experience. J Thorac Dis. 2018 Jun;10[6]:3262-3268. DOI: 10.21037/jtd. 2018.05.144. 


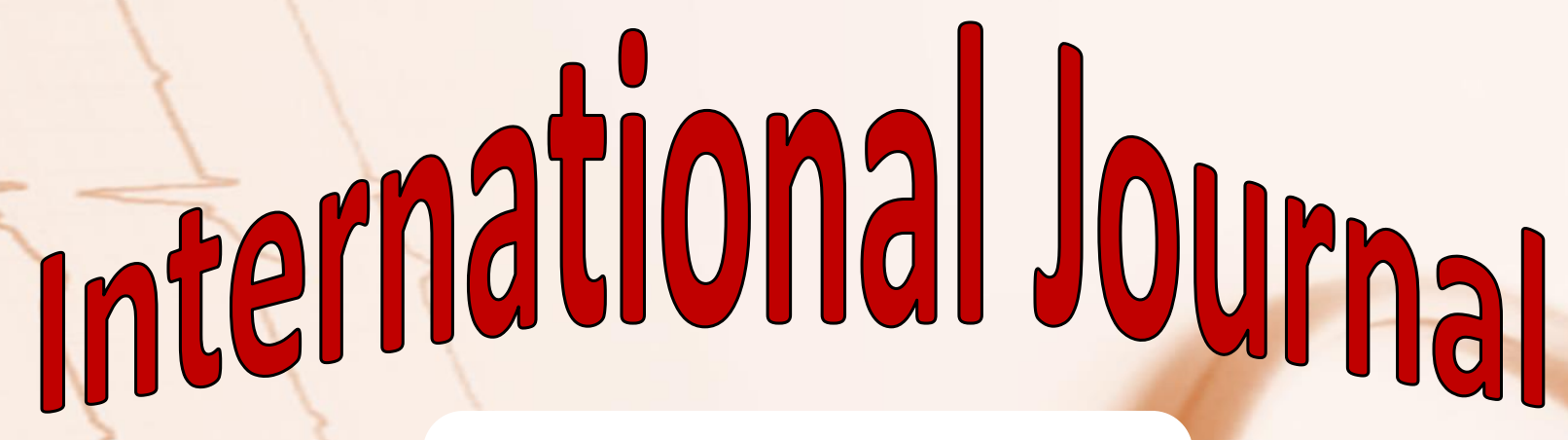

https://ijma.journals.ekb.eg/ Print ISSN: 2636-4174 Online ISSN: 2682-3780

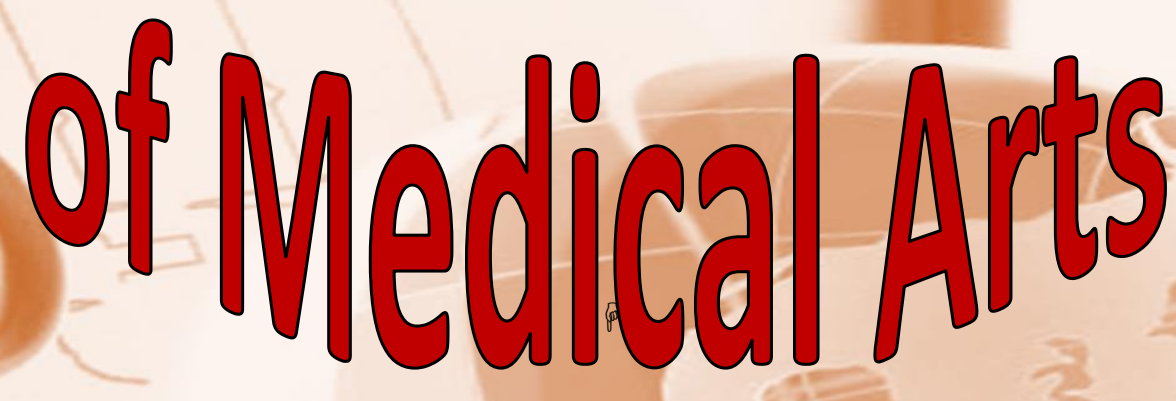

